\title{
The associations between religion, bereavement and depression among Hong Kong nurses
}

Teris Cheung ${ }^{1 * \dagger}$, Paul H. Lee ${ }^{1 \dagger}$ and Paul S. F. Yip ${ }^{2 \dagger}$

\begin{abstract}
Background: This paper is to examine the associations between religion, bereavement and depression among nursing professionals using a cross-sectional survey design. There is little empirical evidence in Asia suggesting that religion may either increase or lower the likelihood of nursing professionals being depressed.

Methods: We analyzed the results of a Mental Health Survey soliciting data from 850 Hong Kong nurses (aged 21-59, 178 males) regarding their mental well-being and associated factors, including participants' socio-economic profile and recent life-events. Multiple linear regression analyses examined associations between religion, bereavement and depression.

Results: Religious faith is weakly associated with lower self-reported depression in bereavement.

Conclusions: Our findings confirm those studies suggesting that religion positively affects mental health and yet healthcare providers have yet to assimilate this insight.
\end{abstract}

Keywords: Bereavement, Depression, Mental health, Nurses, Religion

\section{Background}

The population in Hong Kong exceeded 7 million at the end of 2014 [1]. According to the Basic Law of the Hong Kong Special Administrative Region (HKSAR), all Hong Kong citizens can practice any religion. It has been estimated that approximately $43 \%$ of the Hong Kong population practice some form of religion [2]. Buddhism and Taoism are the predominant faiths in this metropolitan city [2]. However, most research investigating connections between faith and depression has been conducted in Western countries on cohorts living in the West [3]. There is little empirical evidence in Asia suggesting that religion may either increase or lower the likelihood of people-either employed, unemployed or in any specific profession-being depressed.

\footnotetext{
${ }^{*}$ Correspondence: teris.cheung@polyu.edu.hk

'Teris Cheung, Paul H. Lee and Paul S. F. Yip contributed equally to this work

1 School of Nursing, Hong Kong Polytechnic University, Hong Kong, Hong Kong SAR, China

Full list of author information is available at the end of the article
}

\section{Religion and depression}

A growing body of empirical evidence suggests that having a religion is closely associated with better physical and mental health [4], in particular in inhibiting major depression and suicide [5]. Religious congregants show a reduced risk of developing depression [6] and recover quicker [7]. Scholarship has explained these findings through a "buffering hypothesis": through religious activities, individuals are supported by others within networks [8]. These social ties help reduce social isolation and guard against major mental disorder $[4,6]$. Religion also induces optimism and instills hope [4] in providing a coherent framework to interpret life-events [3].

Koenig et al. [3] have recently examined 339 studies (272 cross-sectional, 45 prospective studies, and 22 clinical trials) of the relationship; of the 272 cross-sectional studies, $63 \%(n=170)$ reported a significant positive relationship between religiousness and lower rates of depression; $22 \%(n=60)$ reported no association; $6 \%$ $(\mathrm{n}=17)$ reported greater depression among the more religious; and $8 \%(\mathrm{n}=22)$ reported mixed findings. $1 \%$ 
$(\mathrm{n}=3)$ reported findings that were complex to interpret. Some researchers look more specifically at the association between religious attendance and depression. Ellision and Flannelly [9] found no relationships between these terms in a national sample of African-Americans. Ellision's findings were echoed by Smith et al's [10] metaanalysis of 147 studies covering some 100,000 subjects; this found a weak negative correlation $(-0.096)$ between religiousness and depressive symptoms after controlling for gender as a confounding variable. Other researchers argued that some religious individuals lacking reassuring conceptual frameworks were more vulnerable to the onset of psychiatric disorder [11]. Other researchers studied the physically and mentally ill population. Koenig [7] followed 1000 depressed serious medically ill inpatients aged 50 years and older either suffering from congestive heart failure or chronic pulmonary disease and depressive disorder. The religious characteristics of these patients were compared with a non-depressed control group $(n=428)$. Koenig concluded that the severity of depressive symptoms among the religious was inversely related to religious indicators (religious affiliation, prayer, reading scripture). Previous studies have understood religion as a resource helping patients with medical and physical illness cope.

Other researchers concerned themselves with the likelihood of religious people suffering from depression. Some studies show religiosity is associated with lower odds [12-16]. Other research showed increased odds or no association [17] - again highlighting the inconsistency of researchers' conclusions and failure to arrive at a consensus on the relations between religion and depression.

\section{Religion and bereavement}

How does religion relate to the experience of bereavement? Becker et al.s [18] systematic review of 32 quantitative and qualitative studies found $94 \%$ of studies showed some positive effects of religion on bereavement (22 studies reported positive effects; 6 limited positive effects; 2 no positive effects and one suggested religion aggravated depression). Wortmann and Park [19] recently reviewed 73 articles assessing the relationship between religion and bereavement quantitatively. Having a religion helped people adjust to bereavement. Their later [20] systematic review of qualitative studies found that the experience of loss in bereavement may lead to shifts in fundamental beliefs, including change in and loss of religious faith.

Some researchers focusing on the loss of significant others (next of kin, parents, spouse, children, siblings) have yielded inconsistent results regarding the association of religion and grief. Austin et al's [21] study of 57 such bereaved persons found no effect for religiosity as measured by Beck's Depression Inventory and Shepard Scale but, interestingly, the bereaved subjectively reported fewer depressive symptoms. Recent evidence suggests that having a religion may mitigate stress and depression and facilitate recovery from bereavement [3]. Bereavements cause pain and stress [22]. They may also bring to light contradictions between individuals' global beliefs (e.g. God protects humans from harm) and goals (e.g. a desire to carry on living with significant others). Such discrepancies can give rise to unhappy feelings or anger or blaming God [23]. At the same time, religion may encourage the bereaved to reflect on religious worldviews-with the effect that if bereavement does not mean the loss of their faith, it may end up deepening it and tending to spiritual growth [24].

\section{Depression in nurses}

By 2020, depression is projected to become the second most common cause of disability [25]. Women are at higher risk of becoming depressed than their male counterparts [26, 27]. A recent study in China revealed that, among 1592 nurses, $61.7 \%$ had mild depressive symptoms and $25.1 \%$ moderate to severe symptoms [28].

Yoon and Kim [29] revealed similar results that approximately $38 \%(n=441)$ of registered nurses were experiencing depressive symptoms. Younger or single nurses reported higher levels of depression than that of married counterparts $(\mathrm{OR}=2.88,95 \% \mathrm{CI} 1.32-6.27)$.

Apart from marital status, being forced to act superficially seemed to be the second strongest predictor of depressive symptoms in nurses $(\mathrm{OR}=2.46,95 \%$ CI 1.56 3.86); the third strongest was lack of professional reward or recognition $(\mathrm{OR}=1.99,95 \% \mathrm{CI} 1.07-3.70)$. Recent epidemiological data suggests that the weighted prevalence estimates of moderate to extremely severe depression among 850 Hong Kong nurses came in at 35.8\% (AUTHORS, 2015). Female nurses reported depressive symptoms more often than male counterparts. Marital status, chronic illness, job dissatisfaction, collegial disturbance, physical inactivity, sleep disturbance and poor self-reported mental health were significant correlates of depression in nurses.

Recent local findings from authors [30] have implicated that nurses suffer from individual, interpersonal and work-related stressors and they are at high risk of developing psychiatric morbidity, including depression $[25,31-33]$. Nonetheless, there have been a paucity of research on ethnically Chinese nurses' psychic wellbeing [28]. Nurses are persistently subject to increasing high public and professional expectations which pose mental health risks [34]. Existing research shows a marked 
interest in the association between religion and mental health (or depression) and between religion and bereavement. Research typically studies the general population and the medically or mentally ill. There does not seem to be any study assessing the association between religion, bereavement and depression in a Chinese population. There is as yet no empirical study examining the prevalence of religion among nursing professionals, nor do we have any evidence for the effects of religion on nurses at times of distress. This study represents a first step in examining the association between religion, bereavement and depression in the nursing workforce in Hong Kong. This paper draws on data reported by Hong Kong nurses for their wellbeing and religious belief to shed light on this relationship.

\section{Methods}

\section{Aims}

This study aims to examine the associations between religion, bereavement and depression among nursing professionals in Hong Kong.

\section{Design}

A web-based cross-sectional self-administrative survey.

\section{Participants}

The sampling frame used in this study was extracted from the Association of the Hong Kong Nursing Staff (AHKNS) which comprised over $50 \%(n=24,000)$ of all Hong Kong nurses registered with the Hong Kong Nursing Council [35]. Nurses joined the Association on a voluntary basis.

\section{Ethical considerations}

The study was approved as a social science project by the Human Research Ethics Committee for Non-Clinical Faculties (HRECNCF) and Institutional Review Board of a local university in Hong Kong.

\section{Data collection}

A total of 16,082 (67\%) of the Association's members have registered their emails. The Association sent out a mass email inviting participation in our survey. Written informed consent was obtained from all participants. Anonymity and confidentiality were ensured. A total of 850 purposive samples aged between 21 and 59 years were recruited over a 4-week period from October 2013 to November 2013. The response rate was $5.3 \%$. Sociodemographic and other work-related information was obtained and the questionnaire comprises nine sections and takes approximately $20 \mathrm{~min}$ to complete. The sensitivity of some questions meant a number of emergency helplines were listed on the final page.

\section{Instrument}

\section{Depression Anxiety and Stress Scale 21}

Depression is assessed by the Depression Anxiety Stress Scale $21\left(\mathrm{DASS}_{21}\right)$ [35], a validated, reliable self-report psychological instrument using a 4-point Likert scale measuring past-week depression, anxiety, and stress. DASS $_{21}$ is frequently used to measure the severity of depressive, anxiety and stress symptoms in clinical and non-clinical samples [35-37], possessing well-established psychometric properties in reliably measuring depression, anxiety and stress (at a Cronbach's alpha 0.91, 0.84 and 0.90 respectively). It is also believed capable of differentiating between depression, anxiety and stress [35, 38]. Each item is scored from 0 to 3 . The more severe the symptoms in each dimension, the higher the scores in each subscale. Individuals' sub-score for depression was obtained from the $\mathrm{DASS}_{21}$ to measure the severity of symptoms among respondents. Scores from each dimension were summed up and categorized as 'normal', 'mild', 'moderate', 'severe' and 'extremely severe', according to the DASS manual [35]. The cut-off score for DASS depression is 10 . Scores of $0-9$ is considered normal. Scores of $\geq 10$ were categorized as mild, moderate, severe, extremely severe depression according to the DASS manual [35]. The Chinese validated translation of the $\mathrm{DASS}_{21}$ was used in our study as participants were predominantly ethnically Chinese. One consequence was the exclusion from the study of non-readers of Chinese.

\section{Religious belief}

Respondents were asked three single-item questions regarding their religious belief:

1. Do you have a religion? (Yes/no)

2. What is your religion? (1: Catholicism; 2: Christianity; 3: Buddhism; 4: Taoism; 5: Ancestor worship)

3. Is religion important to you? (Yes/no)

Since our study was not originally designed to measure the effects of religion on mental health and bereavement, thus, respondents were not asked for their intrinsic or extrinsic religious involvement in this study.

\section{Bereavement}

The term "bereavement" was taken to mean the death of first degree relatives, meaning one's spouse, children, parents, next of kin and siblings, good friends/other relatives in the past year.

Respondents were asked two questions about bereavement:

1. Have any of your first degree relatives passed away in the past 12 months? (Yes/no) 
2. Do you have other relatives/good friends who have passed away in the past 12 months? (Yes/no)

\section{Outcome measure}

The study took the DASS ${ }_{21}$ depression sub-score as an outcome measure. Adjusted mean differences were taken to determine variations between religious and non-religious participants bereaved over the past 12 months. The mean difference is significant at 0.05 level (2-tailed).

\section{Data analysis}

Multiple linear regression analysis was used to examine the association between religion, bereavement crisis and the DASS $_{21}$ depression sub-score. Both the crude model and the model controlled for socio-economic variables (gender, age, marital status, household income, chronic illness) were reported, as elsewhere on the grounds that these confounding variables were known to our study as risk factors for depression [30]. The interactions between religion and bereavement on the $\mathrm{DASS}_{21}$ depression subscores were also examined. The statistical analysis was conducted using SPSS version 23.0 (SPSS Inc., Chicago, IL, USA).

\section{Results}

The gender ratio in the Hong Kong nursing population is $7: 1$ (F:M) [39] while that in our raw data sample is $4: 1$ (F:M). Our sample is also comparatively younger. To yield representative findings for the Hong Kong population, the study adjusted prevalence estimates by sampling weights reflecting the size of the population as a whole as suggested by the Hong Kong Nursing Council. Specifically, adjustments were made for gender.

\section{Socio-demographic characteristics}

The majority of the respondents were female $(87.6 \%$, $\mathrm{n}=672)$, frontline nurses $(87.2 \%, \mathrm{n}=740)$. The mean age was between 34 and 44 years old (SD \pm 2.79 ). $55 \%$ were married, $43 \%$ single and $2 \%$ divorced, separated or widowed. $70 \%$ had obtained a Bachelor degree or above, earned a monthly household income between HKD 40,000 and 59,000 and were general nurses. Respondents had an average 10-20 years of clinical experience (Table 1).

A total of $70.9 \%$ of the respondents worked in a shift rotation pattern. Less than one quarter of our sample (22.3\%) suffered from chronic illness. Around 35\% reported sleep problems. In terms of life events, $4.5 \%$ reported bereavement of first degree relatives in the past 12 months while $28.9 \%$ reported bereavement of other friends/relatives in the past 12 months. Current smokers and alcohol drinkers comprised 1.5 and $24 \%$ respectively of the sample (Table 1 ).
Table 1 Socio-demographic characteristics between Christians and Non-christians

\begin{tabular}{|c|c|c|c|c|}
\hline & \multicolumn{4}{|c|}{ Christian faith } \\
\hline & No & (\%) & Yes & (\%) \\
\hline \multicolumn{5}{|l|}{ Gender } \\
\hline Male & 71 & 67.6 & 34 & 32.4 \\
\hline Female & 471 & 63.2 & 274 & 36.8 \\
\hline \multicolumn{5}{|l|}{ Age } \\
\hline $21-24$ & 53 & 68.8 & 24 & 31.2 \\
\hline $25-34$ & 185 & 67.5 & 89 & 32.5 \\
\hline $35-44$ & 176 & 62.2 & 107 & 37.8 \\
\hline $45-54$ & 112 & 60.2 & 74 & 39.8 \\
\hline $55-64$ & 16 & 55.2 & 13 & 44.8 \\
\hline \multicolumn{5}{|l|}{ Education level } \\
\hline Bachelor degree or above & 377 & 63.4 & 218 & 36.6 \\
\hline Associate degree & 68 & 63.0 & 40 & 37.0 \\
\hline Secondary school (form 4-7) & 98 & 66.7 & 49 & 33.3 \\
\hline \multicolumn{5}{|l|}{ Marital status } \\
\hline Single, never married & 233 & 64.5 & 128 & 35.5 \\
\hline Married or cohabitance & 296 & 63.4 & 171 & 36.6 \\
\hline Divorced, separated, widowed & 13 & 59.1 & 9 & 40.9 \\
\hline \multicolumn{5}{|l|}{ Monthly household income (HKD) } \\
\hline $20,000-39,000$ & 157 & 65.7 & 82 & 34.3 \\
\hline $40,000-59,000$ & 200 & 64.1 & 112 & 35.9 \\
\hline$\geq 60,000$ & 185 & 62.1 & 113 & 37.9 \\
\hline \multicolumn{5}{|l|}{ Specialty } \\
\hline General nursing & 365 & 61.9 & 225 & 38.1 \\
\hline Mental health nursing & 178 & 68.5 & 82 & 31.5 \\
\hline \multicolumn{5}{|l|}{ Position } \\
\hline Frontline nurses & 478 & 64.5 & 263 & 35.5 \\
\hline Nurse managers & 65 & 59.1 & 45 & 40.9 \\
\hline \multicolumn{5}{|l|}{ Years of employment } \\
\hline$<10$ & 269 & 66.9 & 133 & 33.1 \\
\hline$\geq 11$ & 274 & 61.0 & 175 & 39.0 \\
\hline \multicolumn{5}{|l|}{ Job satisfaction } \\
\hline No & 209 & 68.1 & 98 & 31.9 \\
\hline Yes & 333 & 61.4 & 209 & 38.6 \\
\hline \multicolumn{5}{|l|}{ Chronic illness } \\
\hline No & 419 & 63.5 & 241 & 36.5 \\
\hline Yes & 123 & 64.7 & 67 & 35.3 \\
\hline \multicolumn{5}{|l|}{ Bereavement (first degree relative) } \\
\hline No & 524 & 64.5 & 288 & 35.5 \\
\hline Yes & 19 & 50.0 & 19 & 50.0 \\
\hline \multicolumn{5}{|c|}{ Bereavement (other friends or relatives) } \\
\hline No & 399 & 66.2 & 204 & 33.8 \\
\hline Yes & 143 & 58.1 & 103 & 41.9 \\
\hline \multicolumn{5}{|l|}{ Smoking } \\
\hline No & 536 & 64.0 & 302 & 36.0 \\
\hline Smoked $<6$ cigarettes a week & 5 & 55.6 & 4 & 44.4 \\
\hline Smoked $>7$ cigarettes a week & 2 & 66.7 & 1 & 33.3 \\
\hline
\end{tabular}


Table 1 continued

\begin{tabular}{lrrrr}
\hline & \multicolumn{4}{l}{ Christian faith } \\
\cline { 2 - 5 } & No & (\%) & Yes & (\%) \\
\hline Current drinker & 413 & 63.7 & 235 & 36.3 \\
No & 104 & 64.2 & 58 & 35.8 \\
Yes (1-2 times/month) & 25 & 64.1 & 14 & 35.9 \\
Yes (daily to few times) & & & & \\
Depressive symptoms & 343 & 62.8 & 203 & 37.2 \\
No & 200 & 65.6 & 105 & 34.4 \\
Yes $^{\text {a }}$ & & & & \\
\hline
\end{tabular}

a DASS_depression score $\geq 10$

\section{Religious belief}

A total of 357 (42\%) respondents reported having a religion, $90 \%$ of whom said religion was important to them. The most common religion was Christianity (28.8\%, $\mathrm{n}=244)$, followed by Catholicism $(7.4 \%, \mathrm{n}=63)$, Buddhism $(5.1 \%, n=43)$, Taoism $(0.7 \%, n=6)$, and Ancestor worship $(0.5 \%, \mathrm{n}=4)$. Some respondents selected more than one religion.

Since most respondents were either Catholics or Christians, these two groups were collapsed and coded into a Christian category. Buddhist, Taoists and ancestor-worshipers and other respondents without religious belief were coded as non-Christian.

Christians had lower mean scores of depression (Mean $=8.07 \pm 8.63$ ) than non-Christians (Mean $=8.57 \pm 8.93)$. Independent sample $\mathrm{t}$ tests showed that the mean score of depression between individuals with or without a religion were insignificant $(t=-0.83, \mathrm{df}=848, p>0.05,95 \% \mathrm{CI}-1.71,-0.70)$.

\section{Bereavement}

A total of 37 (4.4\%) participants had a first-degree relative who died in the past 12 months. Over a quarter of participants $(28.4 \%, \mathrm{n}=241)$ had other relatives or good friends dying in the past year.

\section{Multiple regression analysis}

Christians had lower adjusted mean scores of depression (Mean $=8.99$ SD 1.26, 95\% CI 8.91-9.07) than nonChristians $($ Mean $=12.28$, SD 1.26, 95\% CI 12.00-12.36) when bereaved. A statistically significant relationship obtains between Christians and non-Christians in degree of depression after bereavement $[\beta(-4.59)$, SE 1.35, 95\% Wald CI $(-7.23,-1.94)$, Wald $\chi^{2}=11.57, \mathrm{df}=1$, $p=0.001]$. The goodness of fit (R squared) was $47.8 \%$.

Table 2 reports results by multiple regression analysis after controlling for age, gender, marital status, household income and chronic illness $[\beta(-4.51)$, SE 1.30, 95\% Wald CI $(-7.06,-1.95)$, Wald $\chi^{2}=11.97, \mathrm{df}=1$, $p=0.001]$. Results show that respondents being aged between 25 and 44 and divorced/separated/widowed [ $\beta$ (10.36), SE 4.32, 95\% CI $(1.89,18.84)$, Wald $\chi^{2}=5.75$, $\mathrm{df}=1, p=0.002]$ were significant correlates in distinguishing the level of depression between the religious and non-religious bereaved. The goodness of fit ( $\mathrm{R}$ squared) was $52.1 \%$.

\section{Discussion}

Buddhism and Taoism, interestingly, did not turn out to be a predominant faith. Christianity, however; stood out to be the most predominant faith among our sample. Some of the local public hospitals were subsidized by Christian funding bodies and thus, these local public hospitals have a chapel in situ where nurses can easily access to whenever they need. Easy accessibility and domination of the Christianity faith in healthcare setting may provide a user-friendly platform to encourage Hong Kong nurses to turn into Christianity. There was a dearth of studies examining the proportion of different religious faith specific to Hong Kong healthcare professionals and thus, comparing the religion preference between general population and health professionals was not plausible. Our study showed that the religion preference seemed to vary between general population and nurse professionals in Hong Kong. Future studies may investigate the association between occupation/profession and religious faith across the globe.

Our study found that when respondents had been bereaved, their having a religion significantly lowered their adjusted depression scores in comparison to bereaved non-religious people. Further, respondents aged between 25 and 44 and either divorced or separated were significantly more likely to be depressed. Only very few respondents $(4.4 \%, \mathrm{n}=37)$ had been bereaved of first-degree relatives in the past 12 months. More had lived through the deaths of more distant friends and relatives. It is possible that younger respondents had less experience dealing with bereavement than older people amongst respondents as a whole. As a result, those in this age segment may become more vulnerable to depressive symptoms, especially if they feel inadequately supported by their social network.

Married people tend to be closely attached to others-sometimes to children and a community, as well as a partner. Some scholars have postulated connections between marriage and integration into religious communities and customs [40]. Divorced or separated individuals may be more weakly attached to others than those in married relationships. These respondents may receive bereavement as a significant loss further disrupting their ability to bond or form meaningful social ties.

Research in social psychiatry and social psychology tends to place little emphasis on the macro-level 
Table 2 Adjusted depression level between Christians and non-Christians in bereavement

\begin{tabular}{|c|c|c|c|c|c|c|c|}
\hline \multirow[t]{2}{*}{ Parameter } & \multirow[t]{2}{*}{$\beta$} & \multirow[t]{2}{*}{$S D$} & \multicolumn{2}{|c|}{$95 \%$ Wald Cl } & \multirow[t]{2}{*}{ Wald $x^{2}$} & \multirow[t]{2}{*}{ df } & \multirow[t]{2}{*}{$p$ value } \\
\hline & & & Lower & Upper & & & \\
\hline Intercept & 2.51 & 2.76 & -2.91 & 7.92 & 0.82 & 1 & 0.36 \\
\hline Non-Christians & 3.03 & 1.06 & 0.95 & 5.12 & 8.13 & 1 & $0.004^{* *}$ \\
\hline Christians & $0^{\mathrm{a}}$ & - & - & - & - & - & - \\
\hline No death & 2.24 & 1.03 & 0.23 & 4.25 & 4.76 & 1 & $0.029^{*}$ \\
\hline Death & $0^{\mathrm{a}}$ & - & - & - & - & - & - \\
\hline Non-Christians*No death & -4.51 & 1.30 & -7.06 & -1.95 & 11.97 & 1 & $0.001^{* *}$ \\
\hline Non-Christians*Death & $0^{\mathrm{a}}$ & - & - & - & - & - & - \\
\hline Christians*No death & $0^{\mathrm{a}}$ & - & - & - & - & - & - \\
\hline Christians*Death & $0^{\mathrm{a}}$ & - & - & - & - & - & - \\
\hline Male & 0.44 & 0.72 & -0.98 & 1.86 & 0.37 & 1 & 0.56 \\
\hline Female & $0^{\mathrm{a}}$ & - & - & - & - & - & - \\
\hline \multicolumn{8}{|l|}{ Age } \\
\hline $21-24$ & 1.55 & 1.98 & -2.34 & 5.44 & 0.61 & 1 & 0.44 \\
\hline $25-34$ & 3.88 & 1.72 & 0.50 & 7.25 & 5.06 & 1 & $0.02^{*}$ \\
\hline $35-44$ & 3.78 & 1.69 & 0.47 & 7.09 & 5.02 & 1 & $0.03^{*}$ \\
\hline $45-54$ & 2.06 & 1.72 & -1.32 & 5.44 & 1.43 & 1 & 0.23 \\
\hline $55-64$ & $0^{\mathrm{a}}$ & - & - & - & - & - & - \\
\hline \multicolumn{8}{|l|}{ Marital status } \\
\hline Single, never married & 1.52 & 2.22 & -2.83 & 5.86 & 0.47 & 1 & 0.50 \\
\hline Married/cohabiting & -1.22 & 2.19 & -5.51 & 3.08 & 0.31 & 1 & 0.58 \\
\hline Separated/divorced & 10.36 & 4.32 & 1.89 & 18.84 & 5.75 & 1 & $0.02^{*}$ \\
\hline Widowed & $0^{a}$ & - & - & - & - & - & - \\
\hline \multicolumn{8}{|l|}{ Household income (HKD) } \\
\hline $20,000-24,999$ & 0.96 & 1.45 & -1.87 & 3.79 & 0.44 & 1 & 0.51 \\
\hline $25,000-29,000$ & -1.75 & 1.34 & -4.38 & 0.88 & 1.70 & 1 & 0.19 \\
\hline $30,000-39,000$ & 0.97 & 0.97 & -0.94 & 2.88 & 0.99 & 1 & 0.32 \\
\hline $40,000-59,000$ & 0.81 & 0.73 & -0.61 & 2.23 & 1.25 & 1 & 0.26 \\
\hline$>60,000$ & $0^{\mathrm{a}}$ & - & - & - & - & - & - \\
\hline Chronic illness & 3.78 & 0.74 & 2.34 & 5.22 & 26.33 & 1 & 0.26 \\
\hline No chronic illness & $0^{a}$ & - & - & - & - & - & - \\
\hline Scale & $70.263^{b}$ & 3.44 & 63.84 & 77.33 & - & - & - \\
\hline
\end{tabular}

Dependent variable: DASS depression sub-score

Model: (Intercept), Christianity, Death_binary, Christianity*Death_binary, Gender, Age, Marital Status, Income, Chronic illness

Goodness of fit $\left(\mathrm{R}^{2}\right)=52.1 \%$

${ }^{*} p<0.05,{ }^{* *} p<0.01$

a Set to zero because this parameter is redundant

b Maximum likelihood estimate

mediators and moderators of individual-level relationships [41]. As a result, how macrolevel social processes like religion operate on individual-level relationships remains open to question [40]. Clearly, there is a need to elaborate bi-level models (macro-micro level) to fully understand interactions between individual characteristics and religion, bereavement and depression in different cultural contexts. Cross-national analysis will also be needed to examine whether hypotheses concerning religion-depression relationships for some regions can be usefully generalized, for instance from the West to Asian nations where the effect of faith in shaping personal psychologies is poorly understood [40].

In our sample, $90 \%$ of the respondents with a religion declared that religion was important to them. It is likely that individuals with a religion have both intrinsic and extrinsic religious involvement. The social support and networks established via religion build strong social ties among co-religionists. These networks, and the consolation of religion itself, can help buffer religious people 
from depression following on from bereavement [40]. Some religious people believe in an afterlife, meaning the loss of those they love is not permanent for them. They may interpret bereavement as a form of suffering that will eventually be transmuted to salvation [40]. Prayers and religious rituals may also help them cope, so that bereavement is less traumatic for them than for those without faith.

Our study's findings are consistent findings with highprofile studies [42-44] suggesting certain aspects of religiosity (public religious involvement, intrinsic religious motivation) may be inversely related to depressive symptoms. Of course, religion is always mediated by individuals' cultural context $[45,46]$. Our study also showed that not-bereaved religious people had lower depression scores than not-bereaved non-believers and our study's findings support an association between depression and religious faith [3].

Researchers have suggested religion protects people from their vulnerabilities in ordinary life-situations, then becomes a dampener of depression in bereavement. Since the current study is limited by its self-reporting cross-sectional design, it cannot speculate on the causality of the link between religion and depression. In one hypothesis, individuals could turn to religion for comfort, support, hope, and meaning in difficult circumstances usually inducing depression. In another, people become depressed after finding religion, which prevents their condition from becoming more severe or requiring psychiatric admission.

\section{Strengths of our study}

Our study has certain unique strengths. First, to the best of our knowledge, it is the first exploratory study to examine the association between religion, bereavement and psychiatric symptoms among Hong Kong nurses. Second, it features a control group of non-religious respondents whose depressive symptom scores were compared with those of religious respondents dealing with bereavement. Confounding variables were controlled for in regression analysis and compared with non-adjusted measurement outcomes. Our findings confirm studies suggesting religion positively affects mental health, specifically in highlighting its role as a moderator of depression for the bereaved.

\section{Limitations}

Despite these strengths, the study is limited. Its crosssectional design means that data analysis only describes those statistical relationships between religion, bereavement and depression present in our data. We cannot make any causal inferences concerning relationshipswhich would require a longitudinal design. Respondents' self-reports of their incidence of depression in the study need to be treated with caution, in that they were not validated by any objective measurement of depression using a standardized clinical diagnostic manual (e.g. the Structured Clinical Interview for Depression). Further, reports were limited to a period of 1 week before returning the survey.

Second, less than half the participants (41.4\%) in the study expressed some sort of religious belief. This is lower than in recent surveys conducted both in the USA and in the UK (54 and 70\% respectively) [47, 48]. Nevertheless, we must emphasize that our study is not purely a study of religious nurses in dealing with depression and bereavement but rather, we attempted to disentangle the association between religion, bereavement and depression among Hong Kong nurses. The infrequency of believers other than some form of Christians in the study means it lacks the statistical power to examine associations between other religions, bereavement and depression.

Third, the dataset was not originally constructed for the present study. In consequence, intrinsic (prayers, rituals, experiences) and extrinsic religiosity (affiliation, frequency of church attendance, level of social support) were not measured. Hence, participants' self-report of the importance of religious belief cannot be validated by intrinsic/extrinsic religious involvement. It is difficult to make a causal inference on the impact of religion to those bereaved individuals in our study. The risk of over-orunder estimation of the impact of religious faith on those bereaved individuals may also be possible.

Fourth, participants were asked about the bereavement of (their first degree relatives/friends/close relatives) in the past 12 months. Data emerged may also be subject to recall bias. A multi-methodological approach combining quantitative and qualitative methods is recommended for future studies seeking to replicate results.

\section{Conclusions}

Religious bereaved people reported fewer depressive symptoms than the non-religious. Religion seems to be a moderator in thee terms between faith, bereavement and depression. Religion is a major source of hopefulness in Western traditions, though researchers still disagree on whether it insulates people from the effects of depression. Sociologists' perspectives towards death draw on the notion that a belief in an afterlife is fundamental to promote human hopefulness. Nevertheless, traditional psychiatric or psychological research on hopefulness and hopelessness has yet to assimilate this insight.

\footnotetext{
Authors' contributions

All authors contributed to this manuscript. TC and PSFY designed the study;

$\mathrm{TC}$ executed the study and drafted the manuscript. All authors read and approved the final manuscript.
} 


\begin{abstract}
Author details
${ }^{1}$ School of Nursing, Hong Kong Polytechnic University, Hong Kong, Hong Kong SAR, China. ${ }^{2}$ Centre for Suicide Research and Prevention, University of Hong Kong, Hong Kong, Hong Kong SAR, China.
\end{abstract}

\section{Acknowledgements}

We are grateful to the Association of Hong Kong Nursing Staff for recruiting participants in this study. Special thanks go to Dr. Calais Chan, Associate Professor in the Department of Psychology, University of Hong Kong, who allowed us to use his translated Chinese version of the DASS 21 in our study.

\section{Competing interests}

The authors declare that they have no competing interests.

\section{Availability of data and materials}

The dataset has not been made available for public access in order to protect the privacy of the respondents involved in the study. The survey instrument is not publicly available. For enquiry, please contact the corresponding author.

\section{Ethics approval and consent to participate}

The study was approved as a social science project by the Human Research Ethics Committee for Non-Clinical Faculties (HRECNCF) (Reference No. EA 030813) and Institutional Review Board of a local Hong Kong University. An information sheet containing the aims and purpose of the study was attached on the front page of the survey. Written informed consent was obtained from all participants. Anonymity and confidentiality were ensured. Since some survey questions were sensitive, a telephone directory of professional helplines was listed on its last page.

\section{Publisher's Note}

Springer Nature remains neutral with regard to jurisdictional claims in published maps and institutional affiliations.

Received: 26 July 2016 Accepted: 30 June 2017

Published online: 04 July 2017

\section{References}

1. Hong Kong Census and Statistics Department. Demographic trends in Hong Kong 1981-2011. 2012.

2. Hong Kong Yearbook. Religion in Hong Kong yearbook 2013;20:334-9.

3. Koenig HG, King DE, Carson VB, editors. Handbook of religion and health. 2nd ed. New York: Oxford University Press; 2012.

4. Koenig HG. Research on religion, spirituality, and mental health: a review. Can J Psychiatry. Revue canadienne de psychiatriy. 2009:54:283.

5. Williams DR, Sternthal MJ. Spirituality, religion and health: evidence and research directions. Med J Aust. 2007;21:S47-50.

6. Maselko J, Gilman SE, Buka S. Religious service attendance and spiritual well-being are differentially associated with risk of major depression. Psychol Med. 2009;39:1009-17.

7. Koenig GH. Religion and remission of depression in medical inpatients with heart failure/pulmonary disease. J Nerv Ment Dis. 2007;195:389-95

8. George LK, Ellison CG, Larson DB. Explaining the relationships between religious involvement and health. Psychol Inq. 2002;13:190-200.

9. Ellison CG. Religious involvement and subjective well-being. J Health Soc Behav. 1991;32:80.

10. Smith TB, Mccullough ME, Poll J. Religiousness and depression: evidence for a main effect and the moderating influence of stressful life events. Psychol Bull. 2003;129:614-36

11. King M, Marston L, Mcmanus S, Brugha T, Meltzer $H$, Bebbington P. Religion, spirituality and mental health: results from a national study of English households. Br J Psychiatry J Ment Sci. 2013;202:68.

12. Garroutte EM, Goldberg J, Beals J, Herrell R, Manson SM. Spirituality and attempted suicide among American Indians. Soc Sci Med. 2003:56:1571-9.

13. Koenig HG, George LK, Titus P. Religion, spirituality, and health in medically ill hospitalized older patients. J Am Geriatr Soc. 2004;52:554-62.
14. McCoubrie R, Davies A. Is there a correlation between spirituality and anxiety and depression in patients with advanced cancer? Support Care Cancer. 2006;14:379-85.

15. Nelson CJ, Rosenfeld B, Breitbart W, Galietta M. Spirituality, religion, and depression in the terminally ill. Psychosomatics. 2002;43:213-20.

16. Mofidi FM, Devellis GR, Blazer MD, Devellis TB, Panter MA, Jordan MJ. Spirituality and depressive symptoms in a racially diverse US sample of community-dwelling adults. J Nerv Ment Dis. 2006;194:975-7.

17. McClain-Jacobson C, Rosenfeld B, Kosinski A, Pessin H, Cimino JE, Breitbart W. Belief in an afterlife, spiritual well-being and end-of-life despair in patients with advanced cancer. Gen Hosp Psychiatry. 2004:26:484-6.

18. Becker G, Xander CJ, Blum HE, Lutterbach J, Momm F, Gysels M, Higginson IJ. Do religious or spiritual beliefs influence bereavement? A systematic review. Palliat Med. 2007;21:207.

19. Wortmann J, Park C. Religion/spirituality and change in meaning after bereavement: qualitative evidence for the meaning making model. J Loss Trauma. 2009;14:17-34

20. Wortmann J, Park C. Religion and spirituality in adjustment following bereavement: an integrative review. Death Stud. 2008;32:703-36.

21. Austin D, Lennings CJ. Grief and religious belief: does belief moderate depression? Death Stud. 1993;17:487-96.

22. Stroebe W, Zech E, Stroebe MS, Abakoumkin G. Does social support help in bereavement? J Soc Clin Psychol. 2005;24:1030-50.

23. Exline JJ, Rose E. Religious and spiritual struggles. In: Paloutzian RF, Park $\mathrm{CL}$, editors. Handbook of the psychology of religion and spirituality. New York: Guilford Press; 2005. p. 315-30.

24. Payne AJ, Joseph S, Tudway J. Assimilation and accommodation processes following traumatic experiences. J Loss Trauma. 2007;12:75-91.

25. Chung $C$, Lin M, Ching Y, Kao C, Chou Y, Ho P, Chang H. Mediating and moderating effects of learned resourcefulness on depressive symptoms and positive ideation in hospital nurses in Taiwan. Res Nurs Health. 2012;35:576-88.

26. World Health Organization. Women's Health. 2013.

27. Welsh D. Predictors of depressive symptoms in female medical-surgical hospital nurses. Issues Ment Health Nurs. 2009;30:320-6.

28. Gao Y, Pan B, Sun W, Wu H, Wang J, Wang L. Depressive symptoms among chinese nurses: prevalence and the associated factors. J Adv Nurs. 2012;68:1166-75.

29. Yoon SL, Kim J. Job-related stress, emotional labor, and depressive symptoms among Korean nurses. J Nurs Scholarsh. 2013:45:169-76.

30. Cheung T, Yip PSF. Depression, anxiety and symptoms of stress among Hong Kong nurses: a cross-sectional study. Int J Environ Res Public Health. 2015;12:11072.

31. Lim J, Bogossian F, Ahern K. Stress and coping in Singaporean nurses: a literature review. Nurs Health Sci. 2010;12:251.

32. Lin H, Probst JC, Hsu Y. Depression among female psychiatric nurses in southern Taiwan: main and moderating effects of job stress, coping behaviour and social support. J Clin Nurs. 2010;19:2342.

33. Letvak AS, Ruhm JC, Gupta NS. Original research: nurses' Presenteeism and its effects on self-reported quality of care and costs. Am J Nurs. 2012;112:30-8.

34. Schluter PJ, Turner C, Huntington AD, Bain CJ, Mcclure RJ. Work/life balance and health: the nurses and midwives e-cohort study. Int Nurs Rev. 2011;58:28

35. Lovibond PF, Lovibond SH. The structure of negative emotional states: comparison of the Depression Anxiety Stress Scales (DASS) with the beck depression and anxiety inventories. Behav Res Ther. 1995;33:335-43.

36. Gloster AT, Rhoades HM, Novy D, Klotsche J, Senior A, Kunik M, Wilson N, Stanley MA. Psychometric properties of the Depression Anxiety and Stress Scale-21 in older primary care patients. J Affect Disord. 2008:110:248-59.

37. Oei TPS, Sawang S, Goh YW, Mukhtar F. Using the depression anxiety stress scale 21 (DASS-21) across cultures. Int J Psychol. 2013;48:1018-29.

38. Osman A, Wong JL, Bagge CL, Freedenthal S, Gutierrez PM, Lozano G. The depression anxiety stress scales-21 (DASS-21): further examination of dimensions, scale reliability, and correlates. J Clin Psychol. 2012:68:1322-38

39. Hong Kong Nursing Council. Statistics and lists of nurses. 2014.

40. Stack S, Kposowa AJ. Religion and suicide acceptability: a cross-national analysis. J Sci Study Relig. 2011;50:289. 
41. Joe S, Romer DD, Jamieson PE. Suicide acceptability is related to suicide planning in US adolescents and young adults. Suicide Life Threat Behav. 2007;37:165-78

42. Braam AW, Van DE, Prince MJ, Beekman ATF, Kivel S, Lawlor BA, Birkhofer A, Fuhrer R, Lobo A, Magnusson H. Religion as a cross-cultural determinant of depression in elderly europeans: results from the EURODEP collaboration. Psychol Med. 2001;31:803-14.

43. Koenig HG, George LK, Peterson BL. Religiosity and remission of depression in medically ill older patients. Am J Psychiatry. 1998;155:536.

44. Murphy PE, Ciarrocchi JW, Piedmont RL, Cheston S, Peyrot M, Fitchett G. The relation of religious belief and practices, depression, and hopelessness in persons with clinical depression. J Consult Clin Psychol. 2000;68:1102.
45. Lizardi D, Gearing R. Religion and suicide: Buddhism, native American and African religions, atheism, and agnosticism. J Relig Health. 2010;49:377-84.

46. Colucci E, Martin G. Religion and spirituality along the suicidal path Suicide Life Threat Behav. 2008;38:229-44.

47. Taylor H, Harris P. The religious and other beliefs of Americans. 2003. http://www.harrisinteractive.com.vault/Harris-interactive-Poll-ResearchThe-Religiouness-and-Other-Beliefs-of-Americans-2003-3003-02.pdf. Accessed 1 May 2016.

48. Ashworth J, Farthing I. Churchgoing in the UK. Teddington: Tearfund; 2007.

\section{Submit your next manuscript to BioMed Central and we will help you at every step:}

- We accept pre-submission inquiries

- Our selector tool helps you to find the most relevant journal

- We provide round the clock customer support

- Convenient online submission

- Thorough peer review

- Inclusion in PubMed and all major indexing services

- Maximum visibility for your research

Submit your manuscript at www.biomedcentral com/submit 